\title{
Autopneumonectomy with compensatory lung growth
}

\author{
I Ciric $M D^{1}, M P$ Meyers $M D^{2}$, J Mayba $M D^{3}, N R$ Anthonisen $M D^{1}$
}

I Ciric, MP Meyers, J Mayba, NR Anthonisen. Autopneumonectomy with compensatory lung growth. Can Respir J 2003;10(5):271-273.

A 23-year-old female immigrant from Ethiopia presented with a history of hemoptysis and an abnormal chest $\mathrm{x}$-ray. A computed tomography scan showed that her left lung was greatly shrunken and her right lung was very large but structurally normal. She had a history of multiple respiratory infections as a young child but had been well since the age of five years. Her lung function was within normal limits except for an increased residual volume. It is very likely that her left lung was destroyed early in childhood and that her right lung underwent compensatory growth. She did not show airways obstruction, which is usually seen when compensatory lung growth occurs after surgical removal of lung tissue; this may indicate that, in those cases, the surgery compromised airway function.

Key Words: Compensatory lung growth; Maximal expiratory flow; Pneumonectomy

W hen lobes or lungs are resected in a young mammal, the remaining lung undergoes rapid growth characterized by the formation of new alveolar units, such that as an adult, the single remaining lung has an alveolar number and surface area similar to that of the two lungs of a normal individual (1). This phenomenon has been repeatedly demonstrated in animal models, but has seldom been documented in humans.

\section{CASE PRESENTATION}

A 23-year-old Ethiopian woman who had arrived in Canada one month previously was admitted to hospital for investigation of an abnormal chest x-ray. She had a history of intermittent hemoptysis as a child and adolescent, and had suffered from repeated respiratory infections as a small child; however, these infections had stopped when she was approximately five years of age. She had no other respiratory symptoms. The physical examination was unremarkable except for greatly reduced breath sounds in the left hemithorax and displacement of the heart sounds to the left. The hemogram and blood chemistries were normal, and the Mantoux test and sputum cultures were negative.

The chest x-ray (Figure 1) showed displacement of the mediastinum to the left, with only a small amount of lung visible to the left of the heart in the lower thorax. High resolution computed tomography (CT) scans of the lungs (Figure 2)

\section{Autopneumonectomie accompagnée d'une croissance compensatrice d'un poumon}

RÉSUMÉ : Une immigrante de 23 ans d'Éthiopie a présenté des antécédents d'hémoptysie et une radiographie pulmonaire anormale. Une tomographie assistée par ordinateur a démontré que son poumon gauche était considérablement atrophié et son poumon droit était très gros mais structurellement normal. Dans ces antécédents, elle avait souffert de multiples infections respiratoires lorsqu'elle était jeune, mais était bien depuis l'âge de cinq ans. La fonction pulmonaire se situait dans les limites normales sauf pour un volume résiduel accrû. Il est très probable que le poumon gauche ait été détruit durant son enfance et que le poumon droit ait grossi pour compenser. Elle ne montrait pas de signes d'obstructions des voies aériennes qui accompagnent habituellement une croissance compensatoire des poumons après l'ablation chirurgicale de tissus pulmonaires ; cette situation peut indiquer, dans ces cas, que la chirurgie a compromis la fonction aérienne.

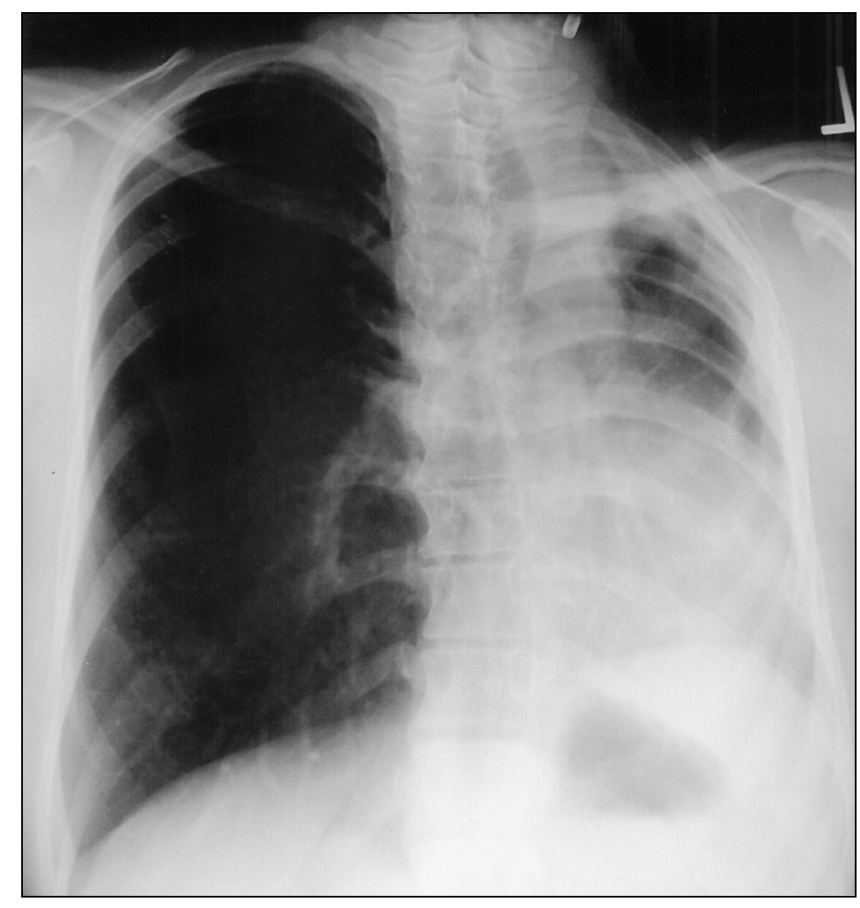

Figure 1) Posterior-anterior chest radiograph demonstrating a marked reduction in the volume of the left hemithorax, with a left shift of the mediastinum. The right lung is enlarged

Departments of ${ }^{1}$ Medicine, ${ }^{2}$ Radiology and ${ }^{3}$ Family Medicine, Health Sciences Centre and University of Manitoba, Winnipeg, Manitoba Correspondence and reprints: Dr NR Anthonisen, RS 319, Health Sciences Centre, 810 Sherbrook Street, Winnipeg, Manitoba R3A 1R8.

Telephone 204-787-2562, fax 204-787-4586, e-mail nanthonisen@exchange.hsc.mb.ca 


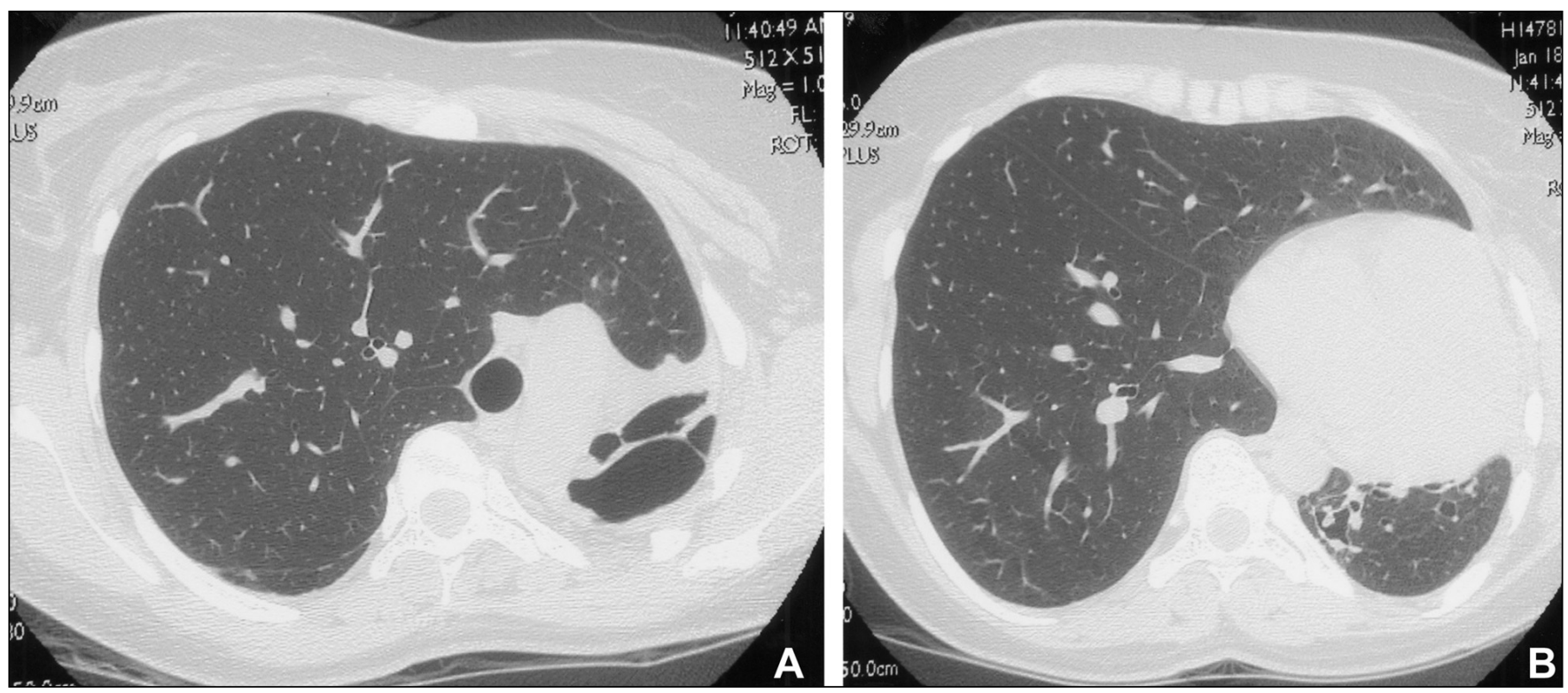

Figure 2) High resolution computed tomography images of the lungs through the level of the aortic arch (A) and lung bases (B) demonstrating an extremely small left lung with foci of cystic change and bronchiectasis. The right lung is enlarged, extending across the midline to the left, but appears structurally normal

TABLE 1

\section{Pulmonary function test results compared with Caucasian normal values}

\begin{tabular}{lcc}
\hline & Result & $\begin{array}{c}\text { Per cent } \\
\text { predicted }\end{array}$ \\
\hline Forced expiratory volume in 1 s (L) & 2.49 & 70 \\
Forced vital capacity (L) & 3.03 & 73 \\
Total lung capacity (L) & 4.88 & 92 \\
Residual volume (L) & 1.95 & 139 \\
Diffusion capacity for carbon dioxide (mL/mmHg/min) & 25.5 & 78 \\
Diffusion capacity for carbon dioxide/alveolar volume & 5.96 & 97 \\
\hline
\end{tabular}

*Predicted normal values for Caucasians (10\% to $12 \%$ higher for Africans)

revealed a greatly enlarged right lung that appeared structurally normal. The left lung was very shrunken, and demonstrated bronchiectasis and cystic changes, with essentially no normal parenchyma. Lung function test results were compared with Caucasian normal values (Table 1) and were within normal limits, except for an increase in residual volume. The patient's arterial partial pressures of oxygen and carbon dioxide were $98 \mathrm{mmHg}$ and $36 \mathrm{mmHg}$, respectively. She was discharged without therapy or follow-up.

\section{DISCUSSION}

In the present case, the patient had a small, nonfunctional left lung and a very large right lung that had undergone compensatory lung growth to the extent that her adult lung function was essentially normal. The cause of the functional left pneumonectomy is not clear. The patient might have had pulmonary hypoplasia in fetal life, with subsequent infections of the hypoplastic lung. However, unilateral pulmonary hypoplasia occurs on the right side much more often than on the left and is usually associated with abnormalities of the mainstem bronchus (2); these were not evident on the CT scan. Alternatively, the left lung might have been destroyed by repeated infections in childhood, which is more compatible with the history and radiological findings. In any event, this degree of compensatory lung growth must be exceedingly rare in humans, because it is the first such case the authors have seen or heard of. There are two points that were raised by the present patient that we believe merit discussion - one is the extent of the compensatory growth, and the other is the absence of apparent airways obstruction.

Immature animals respond to surgical pneumonectomy with compensatory lung growth, while most adult mammals do not (3). Normally, alveolar multiplication occurs for a relatively short time after birth, and it is thought that if lung tissue is lost during this time, the organism can respond with compensatory growth. If an adult animal loses lung tissue, no alveolar multiplication occurs, and the remaining lung simply expands in response to increased stress. This is well illustrated in adult humans who undergo lung resection. The age at which alveolar multiplication ceases in the normal human is not known with precision, but it is very likely to be less than eight years old and may be as young as two to four years old (4). The present patient developed her disease while very young - less than five years of age - presumably while she was still developing new alveoli. Thus, the compensatory growth was likely an amplification of the normal process. Evidence for compensatory lung growth in humans has been found in children who underwent lobar resections for congenital lobar emphysema during the first year of life (5). The increase in residual volume observed in the present patient has been noted in animal models of compensatory lung growth (6) and in one human case of growth consequent to pneumonectomy (5). It may reflect a lack of 'fit' between the lung and the chest wall at low volumes.

Reductions in maximum expiratory flow have been routinely observed in animal models of compensatory lung growth $(7,8)$, as well as in humans with previous resections for congenital lobar emphysema (5). One obvious explanation for this 
finding is that the surgical removal of a lung or lobe involves the removal of associated airways, and compensatory growth of conducting airways does not occur because airway growth is completed in utero in virtually all mammals. Thus, after resection and compensatory alveolar growth, a normal two-lung complement of alveoli is forced to empty through a reduced number and total diameter of airways, with associated reductions in the normal maximum flow. One of the authors investigated this issue thoroughly in a canine model of compensatory lung growth consequent to early pneumonectomy (6). In fact, in adult dogs with compensatory lung growth, maximum expiratory flow was sharply reduced (7). Part of this reduction was due to frictional pressure losses upstream from the flow-limiting segment that determines expiratory flow, but a major portion of the reduction was due to abnormal properties of the flow-limiting segment itself (8). Increased upstream frictional losses would be expected with large populations of alveoli emptying through relatively few airways, but it was difficult to explain the abnormal collapsibility of the flow-limiting segment on the basis of compensatory lung growth. It should be noted that the canine model may differ from the human model in a variety of ways. In particular, canine compensatory growth is uneven (8), with some lung lobes being much more affected than others. This is not obviously the case in humans, and it may be that this unevenness of growth or some other uniquely canine characteristic influences the properties of the flow-limiting segment.

In summary, surgical models of compensatory lung growth in dogs showed airways obstruction, as did children who had surgical resections for congenital emphysema (5). The present patient did not have airways obstruction, though she did have compensatory lung growth. We believe that this may indicate that it is not the compensatory lung growth, but rather the surgical intervention, that stimulated the growth that tended to destabilize the large airways that normally form flow-limiting segments. The preservation of expiratory flows in the present patient may have been because her functional pneumonectomy occurred in the absence of surgery.

\section{REFERENCES}

1. Thurlbeck WM, Galaugher W, Mathers J. The adaptive response to pneumonectomy in puppies. Thorax 1981;36:424-7.

2. Krummel TM. Congenital malformations of the lower respiratory tract. In: Chernick V, Boat TF, eds. Kendig's Disorders of the Respiratory Tract in Children, 6th edn. Philadelphia: WB Saunders, 1998:307-8.

3. Thurlbeck WM. Postnatal growth and development of the lung. Am Rev Respir Dis 1975;111:803-44.

4. Thurlbeck WM. Postnatal human lung growth. Thorax 1982;37:564-71.

5. McBride JT, Wohl MEB, Strieder DJ, et al. Lung growth and airway function after lobectomy in infancy for congenital lobar emphysema. J Clin Invest 1980;66:962-70.

6. Ford GT, Galaugher W, Forkert L, Fleetham JA, Thurlbeck WM, Anthonisen NR. Static lung function in puppies after pneumonectomy. J Appl Physiol 1981;50:1146-50.

7. Arnup ME, Greville HW, Oppenheimer L, Mink SN, Anthonisen NR. Dynamic lung function in dogs with compensatory lung growth. J Appl Physiol 1984;57:1569-76.

8. Georgopoulos D, Mink SN, Oppenheimer L, Anthonisen NR. How is maximal expiratory flow reduced in canine postpneumonectomy lung growth? J Appl Physiol 1991;71:834-40. 


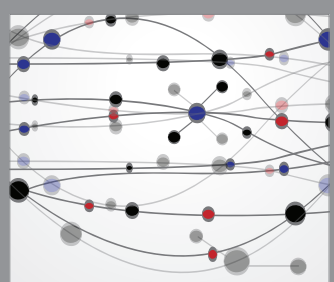

The Scientific World Journal
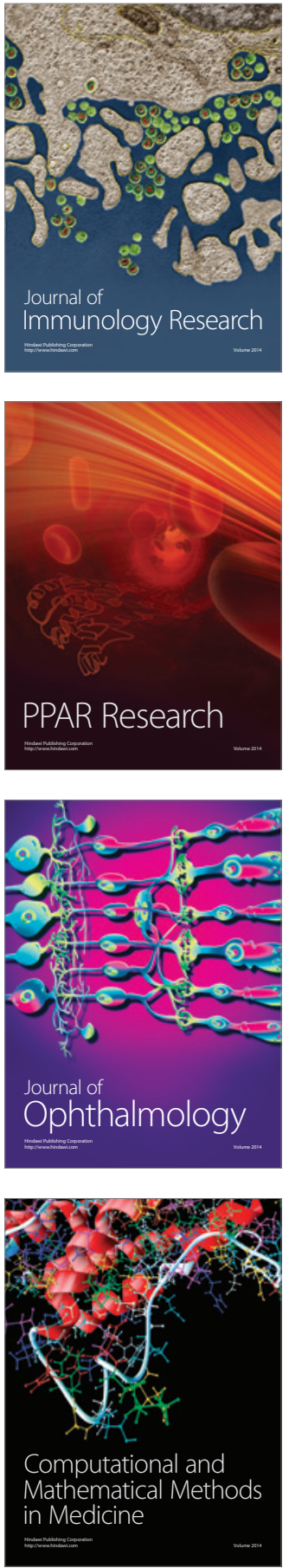

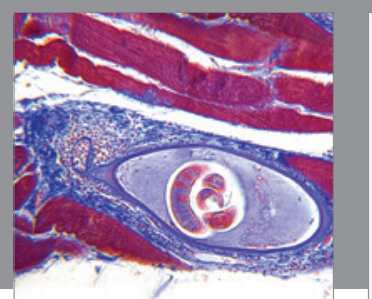

Gastroenterology Research and Practice

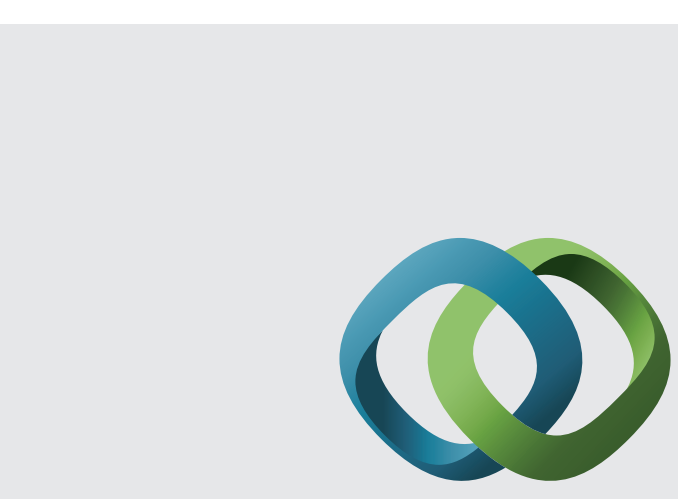

\section{Hindawi}

Submit your manuscripts at

http://www.hindawi.com
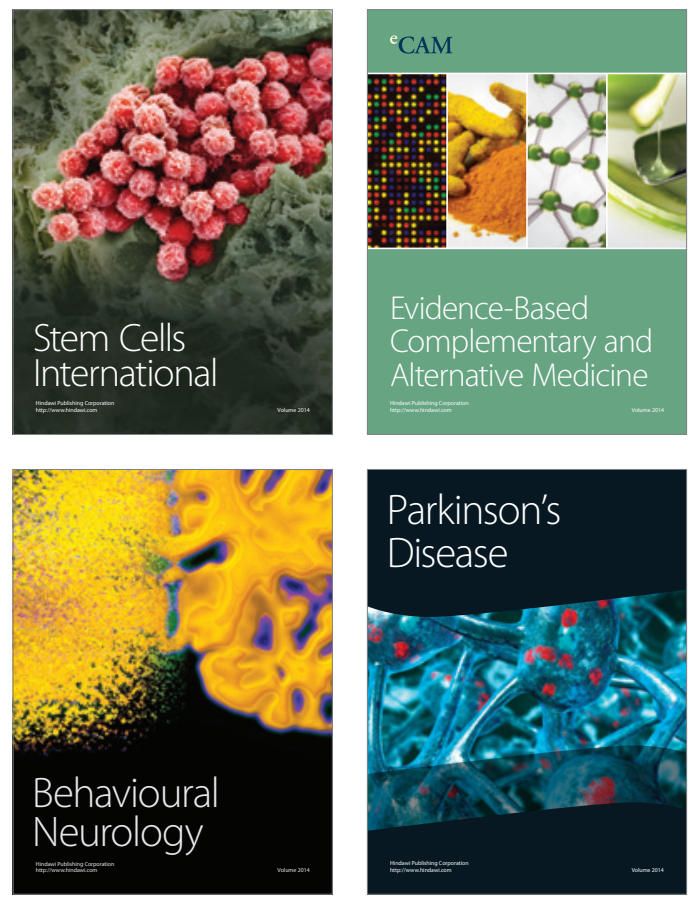
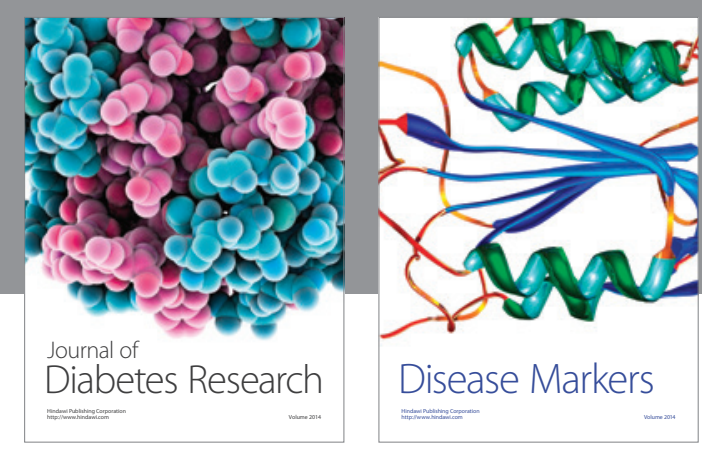

Disease Markers
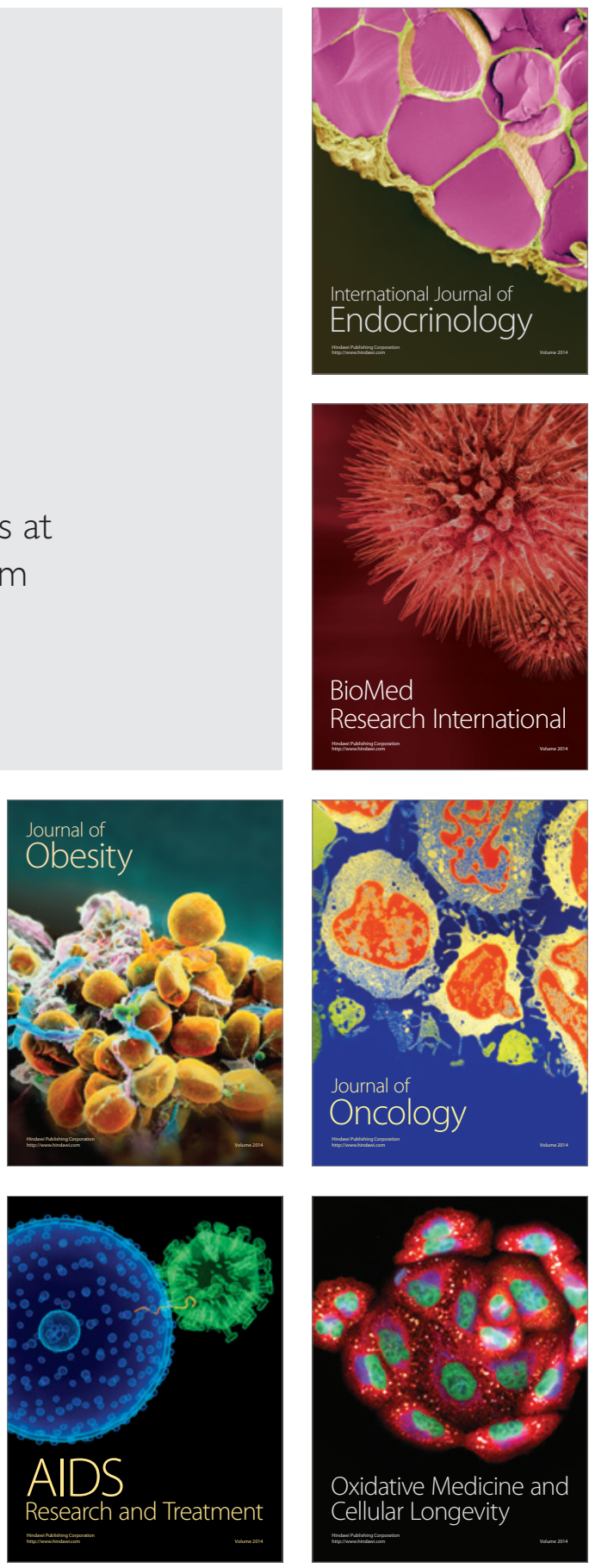